\title{
iSalud sexual y salud reproductiva sin libertad?: El conflicto por el aborto en Argentina
}

\author{
Sexual and reproductive health without freedom?: The \\ conflict over abortion in Argentina
}

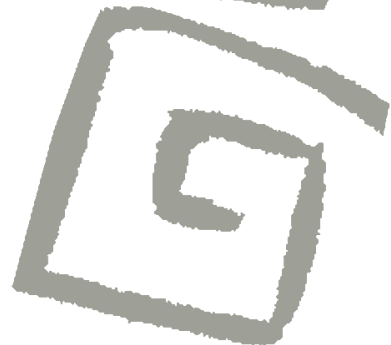

Silvia Levín ${ }^{1}$

${ }^{1}$ Doctora en Ciencias Sociales. Profesora e Investigadora, Universidad Nacional de Rosario, Rosario, Argentina. $\triangle$
RESUMEN El movimiento feminista instaló el conflicto político por el derecho al aborto en 2018 y con él se propone consolidar una transformación en la sustancia de la democracia, -despenalización y legalización- y no solo en su praxis. En este contexto, este artículo se propone describir y valorar el conflicto en democracia sobre la base de las razones y fundamentos del contenido de la disputa, a favor y en contra del aborto, y reseñar las principales disposiciones constitucionales y convencionales que, al regular el aborto, echan luz acerca del universo normativo, del "deber ser", en el que se inscribe como derecho humano. Por último, intentamos explicar cómo se construyó e instrumentó el control político de la soberanía de los cuerpos en un sistema patriarcal, con la legitimidad suficiente y con el poder necesario para perdurar durante siglos. Si bien no existen obstáculos jurídicos para la despenalización y la legalización del aborto, ¿ por qué los intereses de libertad de las mujeres no están plenamente habilitados en todos sus derechos, entre ellos, en los derechos sociales de salud? o ¿qué otros intereses, que no sean los propios, representan esa libertad? PALABRAS CLAVES Aborto; Derechos Humanos; Salud Pública; Argentina.

\begin{abstract}
The feminist movement installed a political debate regarding the right to abortion in 2018, proposing a transformation not only in the praxis of democracy, but also in its substance, through the decriminalization and legalization of abortion. In this context, this article seeks to describe and evaluate the democratic conflict produced based on the reasons and justifications underpinning the disputed content, in favor and against abortion. It also seeks to summarize the principal constitutional and conventional rulings that, by regulating abortion, shed light on the normative universe of what ought to be, in which human rights are inscribed. Lastly, the article attempts to explain how political control over body sovereignty was constructed and implemented in a patriarchal system, with sufficient legitimacy and power to last for centuries. Although there are no legal obstacles to the decriminalization and legalization of abortion, why is that the interests of freedom for women are not fully enabled within their array of rights, including the social right to health? What other interests, other than those of women, does this freedom represent?
\end{abstract}

KEY WORDS Abortion; Human Rights; Public Health; Argentina. 


\section{INTRODUCCIÓN}

El movimiento feminista instaló el conflicto político por el derecho al aborto en 2018 en Argentina, con la presentación del Proyecto de Ley sobre Interrupción Voluntaria del Embarazo (IVE) en el Congreso de la Nación, y con él se propone consolidar una transformación en la sustancia de la democracia -despenalización y legalización- aunque también involucró su praxis. Despenalizar, implica que el aborto no constituya más un delito que criminalice a las mujeres $y$, a partir de esa decisión, pase a constituir el contenido de un derecho humano que obliga al Estado a garantizarlo. Legalizar, supone reconocer la interrupción voluntaria del embarazo de las mujeres como un derecho humano a la libertad de decidir sobre el cuerpo y a recibir por parte del Estado, como garante del derecho social a la salud pública, la cobertura de servicios para la realización de las prácticas correspondientes. La transformación impulsada tiene como horizonte consolidar nuevos derechos que desafían a las desigualdades, y aportar más igualdad de género a la democracia. El derecho traduce la voluntad política, en códigos normativos de licitud e ilicitud ${ }^{(1)}$.

Quienes están en contra del aborto, en el marco de sus intereses conservadores, encaminan una estrategia de statu quo de la democracia, para concretar sus cometidos. La disputa se inscribe en dos escenarios de confrontación: los que defienden el derecho a la libertad del cuerpo de las mujeres y bregan por la despenalización y legalización del aborto, y los que pretenden combatir esa libertad y se oponen al derecho al aborto. El statu quo pretende continuar controlando la libertad del cuerpo de las mujeres. Esa libertad, según la doctrina católica, es de interés social-religioso antes que personal, al garantizar con cada nacimiento la perpetuación de la especie humana. Interferir desde las creencias en una cuestión de interés público, como lo es el reconocimiento y ejercicio de derechos humanos, implica quebrantar el Estado de derecho laico y, con ello, retener las desigualdades de género, como la privación de la libertad de decidir de las mujeres, mediante imposiciones de interés privado religioso.

No existen obstáculos constitucionales ni convencionales del sistema internacional de derechos humanos, para la despenalización ni para la legalización del aborto ${ }^{(2)}$. Si esto es así ¿por qué los intereses de libertad de las mujeres no están plenamente habilitados en todos sus derechos, entre ellos, los derechos sociales de salud? o ¿qué otros intereses, que no sean los propios, representan esa libertad?

La praxis democrática también parece haber sido modificada por el feminismo, tras el debate sobre el aborto, al menos por tres rasgos salientes. En primer lugar, restableció el valor de la democracia deliberativa como fuente de legitimidad de la ley, en la cual el debate público y la confrontación de posiciones y argumentaciones, a favor y en contra del aborto, prevalecieron como prácticas políticas institucionales y contribuyeron a organizar el centro de la toma de decisiones. Más de setecientos oradores y oradoras, provenientes de un amplio espectro, a los que se sumaron expertas y expertos, se manifestaron a manera de dos redes políticas (de actores individuales y colectivos; civiles e institucionales), cada una con posiciones y argumentaciones diferentes (redes ideológicas) en el Congreso de la Nación y lo trascienden.

En segundo lugar, el conflicto también inundó la calle, los hogares, las plazas, las universidades, las escuelas, las redes sociales. A lo largo y a lo ancho del país, se manifestaron activamente, masivamente y pacíficamente. La dinámica se trasladó a la calle y unos y otros redoblaron sus estrategias y sumaron otras acciones políticas a las del Congreso. La participación activa constituye un claro componente de influencia política para la toma de decisiones.

En tercer lugar, las convicciones parecen haber superado, en buena medida, las consignas y los lineamientos partidarios. Las mujeres lograron ejercer un liderazgo transversal, que neutralizó diferencias sociales, ideológicas y hasta algunas religiosas. La participación multitudinaria de adolescentes y jóvenes entre 14 y 24 años constituyó un 
acontecimiento novedoso que ilustra, entre otros, la transversalidad del interés público.

Esta temática, aunque no es nueva en la lucha del movimiento feminista, sí lo es -de manera explícita- en el escenario político nacional actual. El acontecimiento legislativo logró unir décadas de lucha, tramas de alianzas y aspiraciones de cambio. El aborto, como tema y problema legitimado para el debate por el presidente Macri, fue impulsado por el feminismo a la agenda pública, conformó la agenda parlamentaria y se disputó en la agenda de gobierno. Interpela las desigualdades políticas de libertad, que arrastran otras tantas desigualdades, como las económicas y sociales de clase, y que sostiene la institucionalidad democrática vigente. Razones objetivas, de justicia política y de justicia social, avalan las transformaciones feministas promovidas en un Estado de derecho constitucionalmente laico, y buscan desplazar las creencias que aún gobiernan el interés público, aunque pertenecen al gobierno de lo privado.

El aborto es un problema social de Estado que atañe al interés público. Tiene como antecedente inmediato lo acontecido durante la década de 1990 y principios de la década de 2000, con la lucha impulsada en el Congreso de la Nación por la aprobación de una política nacional que garantice el ejercicio de los derechos sexuales y los derechos reproductivos. El desafío feminista ${ }^{(1)}$ fue interpelar al orden patriarcal conservador para acelerar la instauración de uno nuevo que, inspirado en la libertad, se encamine al logro de un equilibrio de poder entre los géneros mediante la adquisición política de ciudadanía plena para las mujeres. Para ese fin, el feminismo se propuso instalar el sexo en la esfera pública y desvincularlo de la reproducción dejando en la voluntad de las mujeres la posibilidad de enlazarlos o no como facultades de ejercicio de los derechos sexuales y de los derechos reproductivos. El orden patriarcal conservador se ocupó de enquistar y vigilar el sexo en el ámbito de lo prohibido y hacerlo prisionero de la procreación. Un verdadero conflicto político con aspiraciones de transformación social.
El consenso alcanzado en 2002 permitió destrabar ese conflicto, con la creación del Programa Nacional de Salud Sexual y Procreación Responsable a través de la Ley 25.673, que garantiza el ejercicio de los derechos sexuales y de los derechos reproductivos en la esfera de la salud, aunque con limitaciones a la libertad de las mujeres. Este reconocimiento institucional marca, para el feminismo, un punto de inflexión, al posibilitar algunas transformaciones importantes, aunque no suficientes, en la sustancia de nuestra democracia. No obstante estos avances y otros posteriores que veremos, la libertad plena del cuerpo de las mujeres no fue reconocida ni garantizada.

Bajo estas coordenadas, este artículo se propone, en primer lugar, describir y valorar el conflicto en democracia sobre la base de las razones y fundamentos del contenido de la disputa, a favor y en contra del aborto. La praxis de la democracia adquiere singularidad en este conflicto y es ponderada, al solo efecto de señalar algunos aspectos de su incidencia en la sustancia, pero no constituye objeto de análisis en sí mismo.

En segundo lugar, se reseñan las principales disposiciones constitucionales y convencionales que, al regular el aborto, echan luz acerca del universo normativo, del "deber ser", en el que se inscribe como derecho humano. Por último, intentamos explicar cómo se construyó e instrumentó el control político de la soberanía de los cuerpos en un sistema patriarcal, con la legitimidad suficiente y con el poder necesario, para perdurar durante siglos. Para ese fin, se explicitarán las inmunidades ${ }^{(3)}$ construidas en el "deber ser" nacional -producto de alianzas entre el derecho, la política y la teología- que constituyen el arreglo institucional que facilitó la instrumentación del control en la realidad (el "ser"). A manera de cierre, procuramos repasar institucionalizaciones conquistadas por el feminismo que, como crónica sintética, acercan respuestas a los interrogantes iniciales.

Este trabajo tiene como antecedente una investigación mayor, correspondiente a la tesis doctoral desarrollada entre 2002 y 2006, en el Doctorado en Ciencias Sociales de la 
Facultad Latinoamericana en Ciencias Sociales (FLACSO), titulada "Los derechos de ciudadanía sexuales y reproductivos de la mujer en Argentina: 1990-2005", dirigida por la doctora Dora Barrancos.

\section{LA CONSTRUCCIÓN POLÍTICA DE LA LIBERTAD Y EL REFUGIO DE LA SALUD}

Consideramos que tanto la despenalización como la legalización del aborto encuentran hoy un escenario político sensible a las desigualdades de género, y propicio para institucionalizar esas transformaciones. Los derechos sexuales y los derechos reproductivos, aún con las limitaciones fundadas en dogmas de una cultura patriarcal conservadora, lograron generar conciencia de género, respaldada por números públicos, mientras la sexualidad y la reproducción ingresaban a la agenda pública, como temas de Estado.

A partir de esa apertura política, a fines del siglo XX y comienzos del XXI, se institucionalizaron sucesivas acciones públicas que respondieron a demandas plurales de la agenda de igualdad de género, ligadas directa o indirectamente a la sexualidad y a la reproducción, y que incidieron de manera efectiva y progresiva en la calidad de vida democrática: Ley 24012 o Ley de Cupo Femenino; Ley 26485 de Protección Integral de las Mujeres y Plan Nacional de Acción para la Prevención, Asistencia y Erradicación de la Violencia contra las Mujeres; reforma del Código Penal que sustituye los "delitos contra la honestidad" por "delitos contra la integridad sexual"; régimen especial de inasistencias escolares para adolescentes embarazadas; Ley 25929 de Parto Humanizado; Ley 26618 de Matrimonio Igualitario; Ley 26743 de Identidad de Género; Ley 26862 de Reproducción Médicamente Asistida; Ley 26150 Programa Nacional de Educación Sexual Integral; Ley 26364 de Prevención y Sanción de la Trata de Personas y Asistencia a sus Víctimas, etc.).

La regulación pública de la sexualidad y de la reproducción fue motivo de conflicto político recurrente en la historia de la democracia en nuestro país. Cuando ese conflicto refiere a derechos, la bibliografía denomina al consenso como consensus iuris ${ }^{(4)}$. Si bien en la modernidad el consensus iuris expresó la ruptura con el contrato de interdependencia divina, en la práctica política las leyes positivas aún se disputan con las leyes divinas la regulación de las relaciones sociales que llevan implícito el reconocimiento de personas sujetos de derechos ${ }^{(5)}$. Esas dificultades de sostenimiento de un Estado de derecho laico restringen de manera ilegítima el tratamiento de las desigualdades de género. El conflicto reciente por el aborto otorgó visibilidad y certeza pública a esta restricción política. Las desigualdades en salud pública y las económicas y sociales son constatadas por datos estadísticos oficiales claramente detallados en el Proyecto de Ley de Interrupción Voluntaria del Embarazo, presentado al Congreso de la Nación el 5 de marzo de 2018.

El conflicto tiene por motivación la formación y defensa de identidades particulares, entendidas como adquisiciones políticas y adquiere carácter político cuando, además de tener el suficiente grado de intensidad para trascender la esfera privada, se pone en juego el reconocimiento político identitario y la definición de fines colectivos ${ }^{(6)}$. El consenso es su contracara y, en principio, representa el reconocimiento recíproco de la pluralidad entre contrincantes, como condición de posibilidad. Mediante la realización de actividades políticas, permite la coordinación de actores alineados en un proceso de integración de resultados en la esfera pública ${ }^{(4)}$.

La lógica del conflicto puede promover la lógica del consenso en la medida que la razón única, basada en el orden moral (lo bueno-lo malo; amigo-enemigo; sacrificialheroico), pueda ser desplazada por la razón humana, basada en el orden plural (justoinjusto; adversario-disidente). Podría el consenso, entonces, construir una orientación política común, representativa de un orden social, que sirva como refugio al interés público. Por otra parte, el tipo de reconocimiento que establecen entre sí los contrincantes también hace a la lógica del conflicto 
y a la posibilidad del consenso. Los enemigos justos, reconocen la rivalidad legitimada en posiciones diferentes. Los enemigos absolutos, no reconocen diferencias, sino que defienden una única causa justa que clausura toda actividad política de cercanía.

La armonía social, y no el conflicto, reina en el orden de la razón única religiosa, dado que al suprimirse la libertad se clausura con ella la pluralidad de elecciones y también las contingencias, que son las que habilitan las disputas. El feminismo defiende la libertad de elecciones (continuación o interrupción) y reconoce las contingencias (embarazos) y motivaciones para el conflicto.

En 2002, el Programa Nacional de Salud Sexual y Procreación Responsable representó el consensus iuris alcanzado como resultado de la lucha por los derechos sexuales y los derechos reproductivos, iniciada a fines de la década de 1980. No se los reconoció como esferas del campo de la libertad del cuerpo de las mujeres, sino del campo de la salud pública. Se excluyó la libertad de decidir en materia de sexualidad y de reproducción y el consensus iuris se refugió en la salud pública.

El derecho a la planificación familiar tuvo un carácter estratégico en ese refugio en tanto habilitó a las mujeres a acceder a cierta cantidad de libertad para decidir en materia reproductiva (número y frecuencia de los nacimientos), pero no a la libertad plena (continuación o interrupción del embarazo). La maternidad continuó siendo una obligación y tuvo siempre garantías de salud pública; la no maternidad no tuvo ni tiene garantías de salud pública. La discriminación por condición reproductiva opera como barrera de ejercicio de la libertad de decidir y de acceso a la salud pública: se incluyen mujeres madres y se excluyen mujeres que no desean ser madres.

El catolicismo conservador, opositor principal a las libertades sexuales y a las libertades reproductivas, entiende a estas facultades como una amenaza a los parámetros de organización y regulación natural de la vida y la sociedad que son los que sostienen su doctrina y su magisterio. Este orden desigual y patriarcal, se sustenta en el anudamiento entre sexualidad y reproducción que lo naturaliza y legitima, en el cual las sexualidades y las identidades de los cuerpos de las mujeres son despersonalizadas para ser objetivadas en lo reproductivo: mujeres madres.

En ese orden, la familia es un "único sujeto comunitario" que se caracteriza por la unidad e indisolubilidad. Está determinada naturalmente a perdurar, no por voluntad individual, sino por designio divino. Al ser "el santuario de la vida", servidora de la vida, anida en ella la base de todos los derechos humanos: el derecho a la vida. La vocación de la mujer es, por abnegación religiosa y altruista, la de ser madre, "defensora de la vida y educadora del hogar". Las mujeres son quienes, en la familia, sostienen y promueven los valores de la vida y la fe; han sido durante siglos "el ángel custodio del alma cristiana de este continente ${ }^{\prime \prime(7)}$. Son quienes dan y defienden la vida. Por tanto, la sexualidad es condición natural y la identidad sexual deviene solo de la objetividad del sexo.

La libertad individual no es inherente a la persona, sino que le pertenece a Dios y ese origen determina la posibilidad y el límite de la libertad. El hombre no es libre por sí mismo, sino por ser una criatura de Dios y su libertad es una "donación divina". La mujer, por el contrario, es inmune a la libertad. Dios no le dona a ella la libertad, sino que la retiene con un interés social religioso: la maternidad es una obligación, como condición para la trascendencia y reproducción de la especie.

La mujer es la única beneficiada por la naturaleza para consagrar la vida. Por ello, la mujer procreadora es tan sagrada como la vida misma, porque cada vez que da vida hace "renacer" a Dios. Cuando se preserva a la mujer procreadora, el orden católico preserva su propia existencia como cosmovisión del mundo. Es despojada del interés propio sobre su cuerpo y sometida al interés religioso de otros.

La disputa feminista no es por una libertad en sentido abstracto, sino concreto, relacionada con los derechos inherentes a la condición de persona que, desde hace siglos, impide a las mujeres ser propietarias de sí mismas ${ }^{(1)}$. Se fundamenta en los derechos personalísimos al entender que tanto la sexualidad como la reproducción son sustratos 
de la persona, que corresponden jurídicamente a la esfera de los derechos subjetivos y otorgan poder individual a aquellas decisiones que se ubican en estos planos. Este registro jurídico impone al poder público deberes de "no hacer" para no afectar las libertades. Se propone fundar una ciudadanía plena en la que la libertad del cuerpo de las mujeres sea una conquista de identidad política. Dicha conquista se sustenta, a su vez, en razones de justicia política, entendida como la necesidad de contar con una igualdad de libertades ${ }^{(8)}$ en la comunidad política. Esa igualdad supone también contar con la misma cantidad de libertad para todas las personas ${ }^{(1)}$.

Por otra parte, la identidad política también se funda en razones de justicia social, es decir, en aquellas circunstancias que inciden en las condiciones y oportunidades materiales y psicosociales de vida. Las desigualdades culturales, económicas y sociales operan como barreras que privan a las mujeres del desarrollo de capacidades y del ejercicio de derechos en sexualidad y en reproducción. La clandestinidad del aborto, seguida del riesgo de muerte, constituye un problema social con crueles manifestaciones de injusticia política y de injusticia social, que sufren las mujeres privadas de la libertad de decidir y de acceso a la salud pública.

La libertad del cuerpo permite a las mujeres completar el despliegue de sus capacidades políticas identitarias. El feminismo, al jerarquizar esa libertad, promueve a las mujeres a la esfera pública de la comunidad política y de la ciudadanía plena. El catolicismo conservador, al negar esa libertad, recluye a las mujeres a la esfera privada de la maternidad y domesticidad, restringiendo su ciudadanía. Sin independencia no se producen condiciones de ciudadanía suficientes para consolidar la inserción plena de las mujeres en la comunidad política.

La salud pública no puede garantizar, por sí sola, condiciones plenas de salud si, además, no se garantiza libertad. El principio de interdependencia de los derechos humanos (civiles, políticos, económicos, sociales y culturales) así lo exige, en la medida que unos precisan de la existencia de otros para su realización; no pueden restringirse unos sin afectar a otros, porque sus resultados siempre están implicados.

Este repertorio de contenidos se ve influenciado por la praxis democrática y se refleja en el proceso decisorio. En el reciente debate por el aborto, la democracia deliberativa, recupera vigencia y legitimidad. La variedad y pluralidad discursiva de múltiples actores, aportó argumentos sólidos y de peso, a favor y en contra, que fueron retomadas en las decisiones parlamentarias. En esa deliberación y en la argumentación quedan explicitados los propósitos de quienes impulsan las transformaciones y de quienes se oponen a ellas.

Fuera del ámbito institucional del Congreso, el protagonismo en la calle fue muy significativo, tanto en términos de alcance, por su masividad, como por la diversidad de estrategias empleadas en las acciones políticas, por ambas redes políticas, que lograron incidir en la toma de decisiones. La transversalidad del interés público fue visible y constatable a través de la participación política activa, multitudinaria y plural. También fue numerosa la participación activa de quienes se pronunciaron en contra.

La sociedad argentina puso de manifiesto su nivel de maduración política y con ella su capacidad de lucha por la institucionalización de la igualdad de género, en esta oportunidad, mediante la exigencia de los derechos humanos a la despenalización y a la legalización del aborto. La paradoja es que la sociedad apoya y demanda el derecho al aborto, pero la clase política que la representa, tanto a nivel del Poder Legislativo como del Poder Ejecutivo, demostró mayoritariamente no aceptarlo. Una vez más, la crisis de la representación política aflora.

\section{DISPOSICIONES CONSTITUCIONALES Y CONVENCIONALES FRENTE AL ABORTO}

El proyecto de ley sobre Interrupción Voluntaria del Embarazo, presentado a la Cámara de Diputados por la Campaña Nacional por el Derecho al Aborto Legal, Seguro y Gra- 
tuito (Expediente $\mathrm{N}^{\circ}$ 0230-D-2018), que fue objeto de debate y tratamiento en ambas Cámaras del Congreso de la Nación en los últimos meses, es constitucional. Exterioriza, además, el efectivo cumplimiento de las obligaciones contraídas por el Estado argentino al ratificar los instrumentos del sistema internacional de derechos humanos, entre ellas las relativas al aborto.

No obstante, en el repertorio opositor, la retórica jurídica de la inconstitucionalidad y la violación a los derechos humanos constituyó uno de los recursos de utilidad, sumado a los confesionales, para fundamentar en el ámbito del Congreso de la Nación, posiciones de legisladores y legisladoras. Nos avocaremos a desentrañar específicamente estos puntos jurídicos.

El argumento que sostenemos es que el proceso de crecimiento con más igualdad y libertad, contribuyó a promover una maduración política de la sociedad que es mayor que la que muestra buena parte de la clase política. Este aspecto, puede ser constatado a través de la participación activa y multitudinaria de la sociedad argentina ante la exigencia del derecho humano al aborto. La sociedad, demandó y apoyó mayoritariamente el aborto. Sin embargo, la clase política, buena parte de la que integra el Poder Legislativo y la mayoría que integra el Poder Ejecutivo, es reticente a estas transformaciones, aún siendo demandas por la sociedad a la cual se supone representa.

En nuestra Constitución Nacional, el artículo 75, inciso 23, establece expresamente que es necesario:

Legislar y promover medidas de acción positiva que garanticen la igualdad real de oportunidades y de trato, y el pleno goce y ejercicio de los derechos reconocidos por esta Constitución y por los Tratados internacionales vigentes sobre derechos humanos, en particular respecto [...] de las mujeres... ${ }^{(9)}$

Seguidamente, el inciso prevé un régimen de seguridad social y de protección del niño desde el embarazo hasta la finalización del tiempo de enseñanza elemental, y de la ma- dre durante el embarazo y el tiempo de lactancia.

La referencia a la igualdad, real y de trato, así como también a los derechos reconocidos por el sistema internacional de derechos humanos respecto de las mujeres, da lugar a interpretaciones favorables al reconocimiento del derecho al aborto. Al invocar razones de igualdad de oportunidades y de trato de todas las mujeres, entendemos que intenta evitar dos situaciones de desigualdad de género. En primer lugar, cualquier discriminación que pueda basarse en condiciones reproductivas para poder acceder a la salud pública. En segundo lugar, cualquier tipo de discriminación de clase al que pretenda someterse a algunas mujeres, como las que están en situación de pobreza sumada a su condición reproductiva no deseada, para poder acceder a la salud pública.

La Constitución Nacional no hace referencia expresa al aborto. Sin embargo, la Convención Nacional Constituyente lo contempló en sus deliberaciones, y la formulación aprobada del artículo 75, inciso 23, parecía habilitar, implícitamente, su consideración. Así, durante el transcurso del debate desarrollado en la $34^{\circ}$ Reunión, $3^{\circ}$ Sesión Ordinaria del 19 de agosto de 1994 de la Convención Nacional Constituyente, sobre el artículo 75, inciso 23, uno de los dictámenes formulados en minoría, que no fue aprobado, proponía otra redacción para ese inciso dado que, en los términos que fue elaborado en el dictamen de mayoría, permitiría la realización del aborto durante los tres primeros meses de embarazo ${ }^{(10)}$.

En el derecho internacional, el aborto ha sido abordado particularmente por los órganos de los tratados (comités) -encargados de vigilar la vigencia y cumplimiento de los derechos humanos por parte de los Estados-; por los tribunales internacionales, en particular la Corte Interamericana de Derechos Humanos que es el intérprete último de la Convención Americana sobre Derechos Humanos; por los trabajos preparatorios de los tratados y convenciones y por los aportes provenientes de las circunstancias de su celebración. 
El denominado corpus juris del derecho internacional de los derechos humanos está integrado, entonces, por un conjunto de instrumentos de interpretación y de órganos de aplicación de sus disposiciones, que regulan las relaciones entre los Estados soberanos, que van más allá del texto mismo del tratado o convención y ofrece en conjunto un abordaje más específico, completo y directo sobre el aborto.

En él, la despenalización es recomendada por la mayoría de los comités de derechos humanos, que están autorizados a interpretar y aplicar esa normativa ${ }^{(11,12,13)}$. Asimismo, dichos comités han puesto el énfasis en asegurar que el acceso a estos servicios, de conformidad con los estándares de derechos humanos, es parte de las obligaciones del Estado para eliminar la discriminación contra las mujeres y garantizar el derecho de estas a la salud así como a otros derechos fundamentales ${ }^{(13)}$. Los avances de los Estados en materia de cumplimiento de derechos son presentados a través de observaciones finales, observaciones generales o recomendaciones generales. Estos, conforman estándares que deben ser utilizados para determinar el cumplimiento de las obligaciones de los Estados, adquiridas en los tratados de derechos humanos.

Centramos el análisis en las disposiciones de los seis principales tratados internacionales de derechos humanos. Mediante una disposición particular, cada tratado crea su órgano de vigilancia (comité) y presenta su mandato ${ }^{(14)}$. Así, la Convención sobre la Eliminación de Todas las Formas de Discriminación contra la Mujer crea el Comité para la Eliminación de la Discriminación contra la Mujer (CEDAW, por sus siglas en inglés); la Convención sobre los Derechos del Niño crea el Comité de los Derechos del Niño (CDN); el Pacto Internacional de Derechos Civiles y Políticos crea el Comité de Derechos Humanos $(\mathrm{CDH})$; el Pacto Internacional de Derechos Económicos, Sociales y Culturales crea el Comité de Derechos Económicos, Sociales y Culturales (CDESC); la Convención Internacional sobre la Eliminación de todas las Formas de Discriminación Racial crea el Comité para la Eliminación de la Discriminación Racial (CERD); y la Convención contra la Tortura y otros Tratos Crueles, Inhumanos o Degradantes crea el Comité contra la Tortura (CCT).

A modo de síntesis, listamos las principales manifestaciones pronunciadas por los Comités (Recomendaciones generales, Observaciones generales y Observaciones finales), de los seis tratados referidos con relación al proceso de evaluación de los Estados parte, respecto al cumplimiento de las disposiciones de derechos humanos sobre el aborto $^{(11,12,13,15)}$ :

- Cinco de los seis comités, a excepción del Comité para la Eliminación de la Discriminación Racial, han manifestado preocupación por los abortos ilegales o realizados en condiciones de riesgo.

- El Comité para la Eliminación de la Discriminación contra la Mujer, el Comité de los Derechos del Niño, el Comité de Derechos Humanos y el Comité de Derechos Económicos, Sociales y Culturales han solicitado de manera explícita a los Estados parte que revisen la legislación que penaliza el aborto.

- La mayoría de los comités, a excepción del Comité para la Eliminación de la Discriminación Racial, han vinculado el aborto ilegal y en condiciones de riesgo con las altas tasas de mortalidad materna. Si bien esa pauta se dicta al momento de analizar explícitamente las restricciones al aborto como una violación del derecho de las mujeres a la vida, cuatro de los seis comités han manifestado preocupación por el impacto que tienen las muertes relacionadas con el aborto sobre los derechos de las mujeres a la vida y a la salud.

- El Comité de los Derechos del Niño ha reconocido la conexión entre la falta de acceso de los y las adolescentes a información y servicios de planificación familiar con la mortalidad materna, que es consecuencia de las altas tasas de embarazos adolescentes, así como de abortos en condiciones de riesgo. Recomienda un mayor acceso a programas y servicios de salud reproductiva para adolescentes como medida para disminuir la mortalidad materna. 
- El Comité de los Derechos del Niño, en los informes realizados en 2010, 2016 y 2018, recomendó expresamente al Estado argentino que debía despenalizar el aborto voluntario.

- Los comités han abordado el problema de las barreras que deben enfrentar las mujeres cuando intentan acceder a servicios de aborto legal.

- El Comité de la Comité para la Eliminación de la Discriminación contra la Mujer y el Comité de los Derechos Humanos han tratado el tema de la objeción de conciencia. El primero sostiene que las disposiciones que permiten la objeción de conciencia, sin garantizar a las mujeres una alternativa para acceder al aborto, violan los derechos sexuales y reproductivos de las mujeres.

- El Comité de Derechos Económicos, Sociales y Culturales, en su Observación No14, reconoce el derecho humano a la salud integral de las mujeres, así como también refiere a él el Pacto de Derechos Económicos, Sociales y Culturales. El proyecto debatido en el Congreso de la Nación, garantiza ese derecho cuando -ante una situación de riesgo o afectación de su salud una mujer, que dispone de su titularidadlo utiliza para interrumpir su embarazo.

- La mayoría de los comités han expresado su preocupación respecto al aborto selectivo, por razones de sexo. El Comité para la Eliminación de la Discriminación contra la Mujer ha hecho un Ilamado a los Estados parte para que desarrollen estrategias para superar esta práctica transformando los estereotipos tradicionales en cuanto al rol de la mujer en la sociedad. El Comité de los Derechos del Niño ha hecho un Ilamado para implementar de manera más rigurosa las leyes que prohíben el aborto selectivo, por razones de sexo.

Las mujeres, según establecen los estándares internacionales de derechos humanos, poseen el derecho a acceder a servicios integrales de salud reproductiva, incluido el aborto, que garantizan el derecho a la vida, a la salud, a la intimidad y a no ser discriminadas. Estos derechos son violados cuando los
Estados tornan inaccesibles los servicios de aborto para las mujeres que los necesitan ${ }^{(12)}$. El derecho internacional de los derechos humanos establece que los Estados pueden ser responsables por: sancionar leyes restrictivas en materia de aborto; por no garantizar el acceso al aborto cuando este es legal y también ante altas tasas de muerte y lesiones de las mujeres que son forzadas a recurrir a abortos en condiciones de riesgo.

Las decisiones en materia de aborto, no solo afectan la libertad sobre los cuerpos de las mujeres, sino que comprometen además los derechos humanos inherentes a su condición de persona, a su dignidad e integridad personal.

Por último, cabe destacar exigencias actuales a algunos de los comités relativas al aborto, para que emitan recomendaciones más efectivas a los Estados parte que deriven en responsabilidades por su incumplimiento y que se basan en disposiciones suyas ya formuladas. Por un lado, el Comité para la Eliminación de la Discriminación contra la Mujer, podría basarse en su Recomendación General №24, para responsabilizar a los Estados parte por no garantizar servicios de aborto seguro y legal a las mujeres que enfrentan un embarazo no deseado ${ }^{(12)}$.

Por otro lado, el Comité contra la Tortura, podría abordar el tema del aborto en sus Observaciones finales, estableciendo que la negativa intencional de proveer servicios de aborto constituye una forma de violencia contra la mujer y que puede ser considerado tortura o trato cruel o inhumano. Implicaría ampliar la definición de tortura o trato cruel, inhumano o degradante para que incluya los casos de negación deliberada a las mujeres de acceso a servicios de salud pública en materia de aborto. Asimismo, la violencia contra las mujeres, incluido el grave riesgo para su vida y su salud, como consecuencia de la negación del acceso a servicios de salud pública para abortos seguros, podría ubicarse en el mandato del comité si lo basa en el Artículo 1 de la Convención contra la Tortura $^{(12)}$.

En síntesis, desde el ámbito jurídico, las leyes supremas de la Nación no ponen 
obstáculos a la despenalización ni a la legalización del aborto.

\section{LAS ALIANZAS PARA EL CONTROL DE LA LIBERTAD: LA INMUNIDAD MATERNAL INDUCIDA}

La democracia argentina ha definido e implementado procedimientos para colar intereses religiosos e institucionalizarlos como si fuesen intereses públicos. Esta afirmación se apoya en el argumento que se controla, jurídica y políticamente, la soberanía de los cuerpos de las mujeres a través de la institucionalización de maniobras de mediación entre el derecho, la política y la teología, que facilitan la imposición pública del orden privado, católico y conservador. Las maniobras, denominadas inmunidad natural e inmunidad maternal inducida ${ }^{(3)}$, lograron ser desafiadas $y$, en buena medida, debilitadas por el movimiento feminista, mediante prácticas políticas del derrotero de la igualdad, de alcance masivo, con fuerte impacto institucional. El movimiento "Ni Una Menos" y "Campaña Nacional por el Aborto Legal, Seguro y Gratuito", respaldan, entre otros pronunciamientos colectivos, esta afirmación.

El cuerpo de las mujeres ha sido provisto para su misión trascendental de una "inmunidad natural", como condición sacramental, que evolucionó luego hacia una construcción política secular para controlar la libertad, que denominamos "inmunidad maternal inducida"(1).

La inmunidad, conceptualmente, es tanto una dispensa como un privilegio. Es percibida como una excepción para algunos respecto a una regla general que rige para todos. Es una condición particular, que no es común a todos en una sociedad. Desde el punto de vista del derecho canónico, comprende no solo la dispensa de una obligación o un privilegio, sino además interrumpe el circuito social divino de la donación de la libertad individual(3).

Los cuerpos de las mujeres son "naturalmente inmunes" a la libertad porque son fuente de creación divina, su naturaleza es dar vida. Si pudieran disponer de libertad, como la disponen los hombres, la cosmovisión del mundo dejaría de ser trascendental para ser finita. La acción de donar la libertad del cuerpo a las mujeres es considerada en sí misma antinatural, porque crea condiciones para disponer de la decisión de dar o no dar vida.

Es este interés religioso, con fines sociales patriarcales, el que sostiene y explica la posición antiderecho al aborto del catolicismo conservador. El aborto, es el único y principal derecho con capacidad de poner en riesgo ese interés, porque la libertad de decidir de las mujeres, continuidad o interrupción de un embarazo, amenaza la esencia y trascendencia católicas.

Por otro lado, la sociedad patriarcal completa la "inmunidad natural" y la seculariza al construir una "inmunidad maternal inducida". Para garantizar la preservación del interés religioso (y social) sobre los cuerpos, a costa del interés individual, se refuerza el dominio maternal, pero mediante un procedimiento de rodeo $^{(3)}$, que desplaza el ritual de la trascendencia. Ese procedimiento, político y jurídico, consistió en neutralizar la libertad para controlarla a través de la salud. Los derechos a la salud sexual y a la salud reproductiva, así como también el derecho a la planificación familiar, garantizan a las mujeres a través de la política nacional de Salud Sexual y Procreación Responsable el ejercicio de cierta cantidad de libertad, pero no una libertad plena. Se protege, entonces, la maternidad saludable sin explicitar la ausencia de libertad plena para ejercitar otras decisiones, como la interrupción voluntaria del embarazo, y la inexistencia de servicios de salud pública para materializarlas.

El derecho es funcional al mecanismo inmunitario, como también lo es la política( ${ }^{(3)}$, al producir reglas que preservan la mujer madre e impiden el libre desarrollo de la mujer que no desea ser madre. Lo logra porque retiene a la mujer madre a través de un mecanismo de compensación: le garantiza el acceso a la salud sexual y a la salud reproductiva como respuesta a una demanda mayor, de ejercicio de la libertad del cuerpo para decidir. La 
"inmunidad maternal inducida" expresa una construcción compleja de alianzas para manejar la protección del cuerpo como objeto de interés político.

La teología, por su parte, promueve el procedimiento inmunitario con tres fines. En primer lugar, se propone resguardar el valor salvífico de la maternidad y, a través de él, controlar la libertad y las consecuencias del pecado. En segundo lugar, logra prevenir la generalización del aborto por su alcance infinito más que prevenir el contagio del deseo de no ser madre. Esta lógica de prevención de la generalización está presente también en la teoría del pecado.

Así, la doctrina social de la iglesia no condena a la mujer que aborta, aunque su conducta sea considerada pecaminosa y objeto de perdón, porque entiende que existieron dificultades de la vida que la llevaron a esa situación ${ }^{(16)}$, pero sí condena a quienes hacen del aborto una práctica profesional o favorecen su autorización y permiten que el hecho se generalice (médicos, parteras, legisladores, funcionarios, agentes de salud).

En tercer lugar, mediante una alianza entre teología y política, se hace prevalecer un "sentido de inmediatez" en las acciones públicas, al sintetizar la maternidad en un preponderante contenido biológico, restringido al control del cuerpo.

\section{PALABRAS FINALES}

El conflicto por el aborto otorgó visibilidad y certeza pública a las dificultades que tiene el Estado de derecho laico para afianzarse y permitir el avance de la institucionalidad de la democracia junto a la vida democrática como experiencias de la cotidianeidad. El interés religioso patriarcal gobierna aún el interés público a costa de restricciones al interés individual y a la igualdad. Se impone a través de privaciones de derechos, institucionalizadas mediante alianzas políticas y jurídicas, e instrumentadas por actores públicos y privados más afines a las creencias que a la democracia de derechos.
Las evidencias históricas son recurrentes respecto de la confesionalidad del Estado, así como también son persistentes y sistemáticas las luchas que enfrentó el movimiento feminista contra el orden patriarcal para aportar más igualdad a la democracia. La praxis del conflicto mostró que la recuperación de la democracia deliberativa en el congreso, así como la multitudinaria participación política de la sociedad en las instituciones y en la calle, constituyen mecanismos plurales de fortalecimiento de la democracia, de transversalidad del interés público y de ampliación de los derechos de igualdad de género. Mientras la sociedad expresó maduración política y sensibilidad por la igualdad, buena parte de la clase política, que conduce la democracia, parece haberse situado muy distante de estos atributos e incluso de las aspiraciones de transformación.

No existen barreras jurídicas de jerarquía suprema, constitucionales ni convencionales de derechos humanos, para la despenalización ni la legalización del aborto. Los arreglos institucionales existentes de carácter normativo, impuestos para cristalizar alianzas restrictivas del aborto, se dan en el derecho común interno. En el plano del derecho civil, se impide el ejercicio del derecho personalísimo a la soberanía de los cuerpos de las mujeres; en el plano del derecho social a la salud, se impide la interrupción voluntaria del embarazo como práctica de salud pública respetuosa de la libertad; y en el plano del derecho penal, se criminaliza a las mujeres que abortan voluntariamente y se legaliza sólo algunas causales para abortar. Los intereses religiosos católicos fueron institucionalizados como intereses públicos.

El 8 de agosto de 2018, la Cámara de Senadores rechazó el Proyecto de Interrupción Voluntaria del Embarazo y no fue ley. Sin embargo, el feminismo creció en protagonismo político, incidencia pública y poder movilizador. Las conquistas feministas por la igualdad fueron progresivas en la lucha por la sexualidad y la reproducción, como escalas hacia la libertad, y de la mano de la salud pública. Configuran una crónica institucional de al menos seis pasos, desde la década de 
1990 hasta la actualidad. Cada escala, con su paso, aportó más derechos a la democracia y con ellos más igualdad de género a la vida social.

Con el horizonte puesto en la transformación, el 8 de agosto sumó un paso. La escala por la conquista del derecho al aborto, está encauzada, repasamos 24 años:

1. Reforma Constitucional de 1994: reconocimiento de los derechos humanos sexuales y reproductivos.

2. Ley 25673 de creación del Programa Nacional de Salud Sexual y Procreación Responsable, del año 2002, y Decreto Reglamentario 1282/2003: ejercicio de los derechos sexuales y los derechos reproductivos, derecho a la planificación familiar (anticoncepción reversible).

3. Ley 26130 de Contracepción quirúrgica: derecho a la anticoncepción quirúrgica irreversible (ligadura tubaria y vasectomía).

4. Guías técnicas y protocolos del Ministerio de Salud de la Nación, 2005-2015: pautas para la atención integral en salud pública de interrupciones legales de embarazos, respetuosas de los derechos sexuales y los derechos reproductivos; Guía para el Mejoramiento de la Atención Post Aborto (Resolución 989/2005 y sus sucesivas actualizaciones 2007, 2009, 2015); Guía Técnica para la Atención Integral de los Abortos no Punibles (Resolución 1184/2010).

5. Fallo de la Corte Suprema de Justicia de la Nación, "F.A.L. s/ medida autosatisfactiva", 2012: derecho al aborto por violación.

6. Presentación y tratamiento del Proyecto de Ley de Interrupción Voluntaria del Embarazo de la Campaña Nacional por el Aborto Legal, Seguro y Gratuito, en el Congreso de la Nación, 2018 (media sanción, Cámara de Diputados, 14 de junio; rechazo Cámara de Senadores, 8 de agosto).

El interés confesional fue progresivamente debilitado como lo constatan los acontecimientos, tanto el interés individual como el interés público están encaminados hacia la soberanía de los cuerpos.

\section{REFERENCIAS BIBLIOGRÁFICAS}

1. Levín S. Derechos al revés: ¿salud sexual y salud reproductiva sin libertad? Buenos Aires: Espacio Editorial; 2010.

2. Gil Lavedra R. La maternidad es una opción, no una obligación [Internet]. 31 may 2018 [citado 1 ago 2018]. Disponible en: https://tinyurl.com/y7mowv4j.

3. Espósito R. Inmunitas: Protección y negación de la vida. Buenos Aires: Editorial Amorrortu; 2005.

4. Arendt $\mathrm{H}$. Los orígenes del totalitarismo. Madrid: Alianza Editorial; 1987.

5. Serrano Gómez E. Consenso y conflicto. Schmitt y Arendt, la definición de lo político. Colombia: Editorial Universidad de Antioquía; 2002.
6. Schmitt C. El concepto de lo político. Buenos Aires: Folios Ediciones; 1984.

7. Juan Pablo II. Homilía del Santo Padre Juan Pablo II: Santa misa en el $\mathrm{V}$ centenario de la evangelización y canonización del beato Ezequiel Moreno y Díaz [Internet]. 1992 [citado 10 may 2018]. Disponible en: https://tinyurl.com/ya63f9gg.

9. Heller A, Féher F. Políticas de la postmodernidad: Ensayos de crítica cultural. Barcelona: Ediciones Península; 1989.

9. Argentina. Constitución de la Nación Argentina [Internet]. 1994 [citado 10 may 2018]. Disponible en: https://tinyurl.com/jcssotv.

10. Honorable Cámara de Diputados de la Nación, Convención Nacional Constituyente. Diario de 
Sesiones: $34^{\circ}$ Reunión, $3^{\circ}$ Sesión ordinaria (continuación) [Internet]. 19 ago 1994 [citado 7 ago 2018]. Disponible en: https://tinyurl.com/ybnyrczf.

11. Meza-Lopehandia M. El aborto en el derecho internacional de los derechos humanos. Santiago de Chile: Biblioteca del Congreso Nacional de Chile, Departamento de Estudios, Extensión y publicaciones, Asesoría Técnica Parlamentaria; 2016.

12. Centro de Derechos Reproductivos. Aborto y derechos humanos: El deber de los Estados de moderar las restricciones y garantizar el acceso a servicios de salud reproductiva seguros [Internet]. Nueva York: CDR; 2010 [citado 10 may 2018]. Disponible en: https://tinyurl.com/yao5pjqu.

13. Naciones Unidas, Alto Comisionado de Derechos Humanos. Serie de información sobre salud y derechos sexuales y reproductivos: Aborto
[Internet]. 2015 [citado 10 may 2018]. Disponible en: https://tinyurl.com/y855j6jd.

14. Naciones Unidas, Alto Comisionado de Derechos Humanos. El sistema de tratados de derechos humanos de Naciones Unidas [Internet]. 2012 [citado 10 may 2018]. Disponible en: https://tinyurl. com/ybbwmcwj.

15. Gil Domínguez A. El proyecto de ley es constitucional y convencional. La Nación [Internet]. 25 jul 2018 [citado 10 ago 2018]. Disponible en: https://tinyurl.com/yd3u2a6b.

16. España, Comisión Permanente de la Conferencia Episcopal. El aborto con píldora también es un crimen [Internet]. 1998 [citado 10 may 2018]. Disponible en: https://tinyurl.com/y9mdzrg2. 